\title{
Catching Up in Crime? Long-Term Processes of Recidivism Across Gender
}

\author{
Fredrik Sivertsson ${ }^{1}$
}

Received: 17 January 2016 / Revised: 26 May 2016 / Accepted: 1 June 2016 /

Published online: 16 June 2016

(C) Springer International Publishing AG 2016

\begin{abstract}
Purpose While males are heavily overrepresented in almost every crime category that may lead to a conviction, there is ambiguity in the predictive value of gender on recidivism patterns over the life course. By using a complete Swedish birth cohort born in 1965 , the present study is able to examine the long-term recidivism patterns in a substantial number of convicted males $(N=27,071)$ and females $(N=7531)$ followed up to age 47 . The aims are to (1) examine the extent to which long-term recidivism patterns are similar in males and females and (2) assess the predictive power of gender on recidivism as these males and females accumulate additional convictions over the course of their lives.

Methods Repeated event history data of criminal convictions is analyzed utilizing detailed information on convictions.

Results The analysis shows that the decline over time in the risk for recidivism, as previously demonstrated in male samples, is replicated for females. In connection with the first and second convictions, males had a stronger tendency toward recidivism than females, but the recidivism risk among females becomes increasingly similar to that found among males as convictions accumulate over the life course. The study also shows that being convicted of a drug offense is a more pronounced predictor of recidivism among females than among males.

Conclusions The results suggest that the predictive value of gender for recidivism is conditional on criminal history. The results are discussed in the light of developmental and life course theories of continuity in crime.
\end{abstract}

Keywords Developmental and life course criminology· Gender. Criminal history· Event history analysis $\cdot$ Repeated events

Fredrik Sivertsson

fredrik.sivertsson@criminology.su.se

1 Department of Criminology, Stockholm University, Universitetsvägen 10A, SE-106 91 Stockholm, Sweden 


\section{Introduction}

There is an association between past and future offending [46]. This tendency toward continuity in offending is well documented in male samples, and over the long term, it results in an ever-smaller proportion of offenders being registered for an increasing proportion of the crimes committed by the cohort to which they belong [21]. In one of the very few studies that have incorporated females into the analysis of continuity in offending, Piquero et al. [51] found that this association captures a strong selection process in both males and females. That is, for every new conviction, there is a relatively large and constant dropout rate and the individuals who persist into higherorder convictions may already have been the high-risk offenders at the time of their first conviction (see also [40]). In this sense, criminal history may be characterized as a selective mechanism where the offending population becomes increasingly homogenous, with regard to risk factors for recidivism, as convictions accumulate.

Since developmental and life course criminology directs its attention at the group of offenders that have passed some reasonable threshold of frequent offending [36], it may seem reasonable that this research context is dominated by male samples. However, given the recent interest in studying the extent to which mechanisms underlying continuity and change are similar in males and females, the reason that females continue to be overlooked in this field is probably primarily linked to a more practical problem, namely a lack of longitudinal datasets that follow a substantial number of female offenders from adolescence to adulthood. An open question, in the light of the results found by Piquero et al. [51], is whether gender is always an important predictor of offending or whether those females who persist are not very different from their male counterparts with regard to recidivism. Nordic population-based register data have an as-yet untapped potential in this regard and provide an opportunity to shed light on patterns of recidivism in a largely neglected group of offenders (see [39]).

The overall aim of the present study is to address long-term recidivism patterns with a focus on gender and criminal history. The overarching question addressed by the study is the following: How does the predictive value of gender on recidivism change as convicted males and females accumulate additional convictions across the life course? In order to further understand the association between gender and recidivism, I examine gender similarities and differences in recidivism tendencies with regard to a number of criminal career parameters derived from conviction data as follows: conviction onset, age at conviction, offense type, and type of sanction. I apply event history analysis to repeated event data on criminal convictions among the members of a complete Swedish birth cohort, comprising all individuals born in 1965, who were resident in Sweden at age 16. The quality of the Swedish register data has made it possible to track the criminal histories of these individuals with good precision over an extensive period of their lives while also taking into account mortality and migration. The study follows these individuals from age 15 (i.e., the age of criminal responsibility in Sweden) to age 47.

While event history methods, which focus attention on the timing aspect of events, are commonly associated with the larger life course literature [29], in criminological research, they have mainly been employed to measure short-term changes in offending tendencies in prison samples [14]. This line of recidivism research has thus not placed the issue of recidivism into the larger developmental context of criminal offending [14]. 
In line with a recent branch of long-term recidivism studies (e.g., [32]), an additional aim of the present study is therefore to emphasize the utility of event history methods when studying continuity and change in criminal offending. In particular, instead of merely focusing on levels of offending, I illustrate how recidivism processes in males and females vary over a long-term follow-up period. As Liu [38] has argued, descriptive work of this kind, with a focus on patterns, constitutes an important first step before digging further into the underlying mechanisms of gendered differences in offending over the life course (p. 94). To my knowledge, this is the first study that utilizes the timing aspect of recidivism to illustrate the dynamics of recidivism over the long run in a substantial number of convicted females and that makes systematic comparisons with convicted males in this regard.

\section{Background}

\section{Gender Similarities and Differences in Criminal Careers}

Male offenders outnumber female offenders in all societies and historical periods for which records are available [27]. In a recent review of gender, offending, and the life course, Macmillan and McCarthy [41] conclude that this pattern is largely consistent across the life course - while there are several similarities between males' and females' offending patterns, the main difference is that males are overrepresented in terms of magnitude across all life stages (see also [31]). Both in males and females, the peak age of offending occurs in late adolescence and is followed by a consistent decline through the transition into emergent adulthood and beyond [10, 30, 33, 38, 58]. Previous research, although limited, has also found that the association between past and future offending applies to both male and female offenders [3, 34, 45, 51]. For example, in the Dunedin Study, Moffitt et al. [45] found that the female sample had a similar concentration of offences as the males in terms of both self-reported offending and convictions. Moreover, studies using the group-based trajectory method have found that there are latent classes of offenders in both male and female samples [22] and that there is a group of more or less persistent offenders that follows a relatively high and stable offending trajectory among both males and females [4, 10, 17].

There are, however, some additional gender differences in criminal careers, besides the overall higher participation rate among males, which are important to highlight in relation to the present study. First, the shape of the age-crime participation curve has been found to be more pronounced among males, with a distinct peak, whereas it is flatter among females. For example, Wikström [58] found that the male participation rate was 23 to 25 times as high as the female participation rate at ages 16 to 17 , but only around five times as high at age 25. Similarly, in one of the longest existing follow-up studies, stretching from age 12 to age 72, Block et al. [10] found that the magnitude difference in participation rates between males and females was relatively high in late adolescence, but hardly distinguishable in middle to late adulthood. Thus, there is a tendency toward convergence with age in male and female offending rates, and this is mainly due to a comparatively large drop in male offending tendencies following the transition to adulthood. 
Second, the first encounter with the criminal justice system occurs, on average, later in life for females than for males [22], and while adult-onset offending is rare in males, it appears to be more prevalent in females $[4,8,10,20,33]{ }^{1}$ In the Criminal Career and Life-Course Study, Block et al. [10] found that the peak age of official onset occurred at age 29 for females and age 22 for males [10]. Moreover, the results showed that as many as $19 \%$ of the females were convicted for the first time subsequent to age 45, indicating the presence of an adult-onset group among females. Similarly, in the Project Metropolitan Cohort Study, Andersson et al. [4] found an adult-onset offending trajectory within the female offending population that was not found among the males.

Third, while previous research suggests that both males and females who persist in crime tend to be versatile with regard to offense types, as opposed to specialized [17, 20,42], there is some gender diversity in the prevalence of offense types. Given the magnitude difference in offending, males tend, with few exceptions, to be overrepresented in almost every offense category. The gender ratio is particularly large when it comes to violent offending [56]. For example, in a large-scale Finnish criminal career study, Elonheimo et al. [24] found that males were overrepresented in every offense type in absolute terms, but particularly in violent and traffic offenses (p. 1271). However, when examining the male and female within-group variation in offense categories, their results showed that property and drug offenses were, in relative terms, more common among females than among males (see also [8, 20, 25, 33]). Substance abuse has, in general, been highlighted as an important factor for persistence in and desistance from crime [44, 48], but particularly among females [56, 57]. Longitudinal qualitative studies provide support for the importance of drug dependency in female processes of desistance. For example, in an analysis of narratives with 49 female ex-offenders, Leverentz [37] found that much of the offending was in some way related to drug use, in terms of either drug-related offenses or propertyrelated offenses to support drug addiction. In in-depth interviews with female parolees, Opsal [50]) was able to highlight the importance for the females to create an identity that was completely different from their drug using pasts.

\section{Gender, Criminal History and Recidivism}

While it is undisputed that males are overrepresented in offending across the life course, a number of studies have shown that once females have entered the criminal justice system, the difference between the rates of (re)offending among males and females is smaller than that found in comparisons of overall male and female offending rates [7, 23, 47, 53, 57]. For example, Uggen and Kruttschnitt [57] found that after 6 months, about $90 \%$ of the females remained in a state of non-offending relative to about $77 \%$ of the males.

\footnotetext{
${ }^{1}$ An important point made by McGee and Farrington [43] is that the identification of adult-onset offending is highly dependent on the measure employed. In the Cambridge study, they found that everyone who had committed their first officially recorded offense in adulthood had some self-reported offending in childhood and adolescence. I would therefore like to highlight the fact that the present study is based exclusively on conviction data and that the focus is not on the existence of adult-onset offending but rather on relative differences between males and females in official records.
} 
The gender difference is even smaller when individual offending frequencies, or lambdas, ${ }^{2}$ are compared in adulthood. For example, Wikström [58] found that there was practically no difference between the male and female lambdas at age 25; the females who offended at this age did so at almost the same rate as the males (p. 72; see also [10]).

It is important to highlight the fact that those criminal career and recidivism studies that have examined gender similarities and differences in patterns of offending have usually employed a bivariate approach. As Steffensmeier and Allan [56] states, "Care must be taken to avoid confusing gender effects with other subgroup effects" (p. 483). For example, in the study by Uggen and Kruttschnitt [57], the male and female samples differed significantly in relation to a number of factors that are known correlates of (re)offending. The females were older, and they had longer educational histories, fewer previous arrests, and a lower risk score with regard to the perceived risk of being incarcerated if arrested (p. 352). The question then becomes whether the gender variable captures these other correlates and, by extension, whether it is these other characteristics that influence recidivism rather than gender per se. Indeed, when adjusting for a number of confounders, Uggen and Kruttschnitt [57] found that the impact of prior offending on the risk of rearrest was greater for the females than for the comparable males (see also [53]). Similarly, Cauffman et al. [17] studied male and female offending trajectories based on self-reported offending and concluded that while there are widespread gender differences in offending at the population level, male and female offenders who are drawn from similar backgrounds are very similar in their patterns of offending (p. 262). The mixed methods approach by Giordano et al. [28] provides a similar picture in which stories of change among marginalized male and female offenders overlap to a considerable degree.

An aspect that is related in many ways to the previous point is that criminal history may modify the predictive value of gender on recidivism. MacLeod et al. [40] analyzed recidivism probabilities in a 1953 birth cohort of males and females and found that within their low-risk categories of male and female offenders, the probability of recidivism was lower among females than among males, which are 0.19 and 0.35 , respectively (p. 42). In the high-risk category, however, the recidivism probability among females was very close to that found among males, which are 0.81 and 0.84, respectively. Similarly, Andrews et al. [5] conducted a meta-analysis of five datasets of males and females in order to validate the extent to which risk instruments for recidivism were gender-neutral and concluded that high-risk cases were high-risk cases, but the moderate- and lower-risk women were recidivating at rates substantially lower than the moderate- and lower-risk men were (p. 127). Hence, given that risk accumulation may be translated into criminal history, there is reason to believe that gender will have some predictive value among males and females convicted once or only a few times, but that this predictive validity will diminish in the transition to higher-order convictions.

\footnotetext{
${ }^{2}$ Lambda is defined as the mean number of criminal events per active offender at a specific age and should not be confused with incidence measures in many other disciplines [12]. Hagan and Palloni [29] argued that lambda is indeed a summary measure of the combined hazards of criminal events over a specified period of time.
} 


\section{The Current Study}

The current study is guided by a dynamic view on continuity and change in offending [16]. Acknowledging the timing aspect between criminal events by employing event history methods has, in this regard, been influential in recidivism research. Traditionally, recidivism research has concerned itself with determining whether or not someone who has offended in the past is at risk of offending in the future. In contrast to developmental and life course research, this research context has been more policy oriented, primarily concerning itself with the effects of criminal justice interventions on recidivism in prison samples. It has therefore focused on much shorter observation windows of only a few years [14]. The time lapse between two criminal events is usually measured in order to discriminate between recidivists in their rate of recidivism, based on an assumption that a short relapse time indicates a strong recidivism tendency. The manner in which recidivism tendencies vary with time is usually illustrated by means of the so-called hazard curves, which may be defined as the conditional probability that an individual experiences a rearrest/reconviction at a certain point in time given that the individual has not yet been rearrested/reconvicted (i.e., is still at risk) [2].

Bushway et al. [14] have argued that much can be learnt from the interplay between developmental and life course criminology and recidivism research. There is a common ground, they argue, in that the methods used in these research contexts are dynamic as opposed to static - trajectory models usually measure long-term change in the propensity to offend, while hazard models usually measure short-term change in the propensity of offend (p. 91). Recently, there has been an interest in studying hazard curves for recidivism over a long-term observation period in order to extend the knowledge on continuity and change in offending. One branch of long-term recidivism studies, also called "redemption studies," has compared hazard curves among different groups of offenders and non-offenders and has been able to nuance the rather static idea that previously recorded offenders are always at higher risk of a new criminal event than non-offenders (e.g., [13]). In contrast, these studies show that the predictive value of a prior criminal record is highly dependent on the time that has passed since the previous criminal event, and generally, they find that after around 7 to 10 years without a new registered crime, the risk of recidivism among those with prior convictions is not larger than the risk of a first conviction among individuals with a clean slate ([15], p. 33).

Long-term recidivism research builds on a well-documented recidivism pattern; the risk of recidivism is highest close to the previous criminal event, after which there is a steep decline, and then a gradual leveling off as time passes (see [49]). In doing so, long-term recidivism research has provided examples of an innovative approach in which the timing aspect of recidivism is used together with a long-term follow-up period to highlight the dynamics of recidivism. The same idea is employed in this study, but instead of comparing offender and non-offender groups, the focus is directed at differences between convicted males and females. In addition to the hazard curves, this study illustrates the recidivism process by means of cumulative probability functions. Cumulative probability functions describe the proportions of the compared groups that have recidivated up to a certain point in time. Even if the speed of recidivism is more pronounced at the beginning of the follow-up period for one group relative to another, the other group may "catch up" in a later phase, meaning that the 
two groups end up having the same overall recidivism probability (for an illustration, see [9]). Cumulative probability functions, in combination with a long observation window, may therefore be used as a descriptive tool to separate the speed of recidivism from the overall recidivism risk.

Finally, while recidivism research has traditionally employed event history methods to analyze the time to a single recidivism event, Hagan and Palloni [29] have suggested that event history methods may also be used to study continuity in offending by acknowledging the repeated event structure of criminal records:

For all those involved in a first criminal event, there is a hazard of involvement in a second criminal event, possibly dependent on the time since the first event and other covariates. The same applies to those involved in later (i.e., higher order) events. In each instance, the order-specific hazards characterize the entire process (p. 96-97).

The use of this approach thus involves a hierarchical data structure, in which several time points (i.e., recidivism events) are nested within an individual [2]. A defining characteristic of this repeated event structure is that it prevents earlier observations relating to a given individual being causally dependent on later observations relating to the same individual, because the events occur in a sequentially ordered process [26]. As Ezell et al. [26] have noted, this approach may provide critical insights into the dynamics of a developmental process because it opens up the possibility for the effects of covariates to change over course of the event process (p. 149). In this regard, the emphasis of the present study is focused on examining whether the association between gender and recidivism changes as convicted males and females accumulate additional convictions over their lives.

\section{Data and Method}

The original study population comprised all individuals born in 1965 who were resident of Sweden at age 16-a total of 122,308 individuals (see [6]). From this population, I selected every individual that had a conviction between the ages of 15 and 47 (i.e., the follow-up period). This selection generated a total of 34,602 convicted individuals, of whom 27,071 (78.2\%) are males and $7531(21.8 \%)$ are females. Convictions data were collected from the Swedish register of convictions maintained by the Swedish National Council for Crime Prevention, and mortality and migration data were collected from the National Board of Health and Welfare and Statistics Sweden. Because every individual in Sweden has a unique personal identification number, it has been possible to link these registers to the study population (for an overview of the potential of Nordic registers, see [39]). The Swedish conviction register covers the period from 1973, which allows for the follow-up of an extensive number of convicted males and females from age 15 (i.e., the age of criminal responsibility in Sweden) into their late 40 s. In terms of long-term recidivism, this is an observation window spanning over 30 years for individuals who were convicted for the first time during adolescence.

A conviction in the Swedish context comprises court sentences, fines imposed by the prosecutor, and waivers of prosecution, which are based on an admission of guilt by the suspect. Swedish conviction data have a relatively high degree of coverage in relation to the number of crimes committed. This is because the Swedish police and 
prosecutors are bound by the legality principle, which means that they must report all crimes that they become aware of and the handling of the criminal act is, in this phase of the criminal justice process, not negotiable [35]. Moreover, the Swedish police do not have a sanctioning mandate other than to impose fines for minor traffic offenses such as speeding. These minor offenses are thus excluded from the conviction register by definition.

\section{Estimating the Process of Recidivism}

The quality of the Swedish registers has made it possible to specify the timing of criminal convictions, mortality, and migration events with good precision. For every recorded conviction over the follow-up period, a total of 107,421 convictions, the date for the sentencing decision was available and for a majority of the cases, also, the date when the crime occurred according to the police report (78,249 cases). The approach employed has focused on analyzing the "gap time" between every two convictions, and the clock was therefore reset for each new conviction (see [26]). The process for the first spell started at the date of the first conviction, and the event was defined as the date when the second conviction occurred. The process for the second spell started at the date of the second conviction, and the event took place on the date when the third conviction occurred and so on. ${ }^{3}$ When an individual was given a prison sentence, the process for the next spell started at the estimated time of release in order to adjust for exposure time (see also [19]). ${ }^{4}$ The data does not include the exact date for when starting to serve a prison sentence or when released from prison. Time spent in prison was estimated on the basis of the sentence imposed, assuming that the actual period of imprisonment was two thirds of the imposed sentence (see also [3]). The release after two thirds of the imposed sentence is a standard procedure in the Swedish criminal justice system regardless of the sex of the offender. ${ }^{5}$ Individuals were right censored at the end of the follow-up, at the date of death, or at the date of emigration. Individuals

\footnotetext{
${ }^{3}$ When the crime date in a subsequent conviction was recorded to have occurred prior to the crime date of the previous conviction, it was assumed that this was a not a recidivism event but was rather the result of the second offence having a longer criminal justice processing time than the previous offence. These 5929 cases (around $5 \%$ of the observations) were thus excluded. The median number of days between the date of the offence and the conviction date was very similar across gender-153 days among males and 156 days among females. Nonetheless, as an additional check of the robustness of the results, all of the analyses were reestimated using only those cases for which the date of the offence was available. In these analyses, the process started on the date of the offence recorded in a previous conviction and the event was defined as the date on which a subsequent offence occurred according to the subsequent conviction. The duration was thus estimated on the basis of these two offence dates. The initial results were replicated without any substantial differences. The results of these analyses are available on request.

${ }^{4}$ It may be debated whether it is justified to adjust for differences in time at risk to reoffending as a result of incarceration. Considering that the incapacitation effect is one of the justifications for custodial, Sirén and Savolainen [55] argue that it is not clear, from a public safety perspective, why this effect should be excluded from the analysis (p. 86). However, since the focus in the present study is on comparing male and female recidivism patterns and since it may be assumed that the males are subject to a gender penalty in the context of criminal justice processing [18], an adjustment for exposure time due to incapacitation was deemed justified. ${ }^{5}$ One hundred four observations were of negative duration due to the fact that these individuals were in prison at the end of the observation window. These cases were excluded because a new spell did not begin. Observations in 1868 were of negative duration due to the occurrence of a reconviction prior to or on the same day as the estimated release from prison. In these cases, it was assumed that the negative duration was due to early release or a parole violation. These duration times were recoded into 30 days. A dummy variable was created to test whether this affected the results in any way.
} 
who emigrated and returned were interval censored during the time that they lived abroad.

Cox proportional hazard models were estimated in the multivariate analysis. The main advantage of this semi-parametric method, in contrast to fully parametric models, is that no assumptions as to the specific distribution of duration dependency have to be made [2]. ${ }^{6}$ Robust standard errors were estimated to account for dependency in the repeated event structure [2].

\section{Measures}

In addition to information on the timing of crimes and sentences, information from the conviction register was also used to construct variables measuring the conviction order, the age at conviction, offense type, and type of sanction. Because of the repeated event structure, all of these variables are to be characterized as timevariant. In other words, they refer to the time of the conviction that marks the start of a given spell. Conviction order was treated as a categorical variable using the first reconviction process as the reference category $(0)$; the second reconviction was included as a separate dummy variable, the third and fourth were collapsed and included as a single dummy variable, and the fifth to the ninth were collapsed and included as a further dummy variable, as were all additional reconvictions from the tenth and above. Age refers to the chronological age at conviction and was included as a continuous variable together with a squared age term in order to account for the non-monotonic age-crime association. A variable measuring age at first conviction was included to account for the later onset of convictions among females relative to males. The offense type refers to the principal offense in the conviction (i.e., the most serious offense according to the penal code). The conviction register contains detailed references to the relevant penal code provisions, and the principal offense may be described in terms of violations of up to three different sections of the code. This information has been used to code six offense categories as follows: violence, ${ }^{7}$ property, ${ }^{8}$ drug,${ }^{9}$ fraud,${ }^{10}$ vandalism, ${ }^{11}$ and traffic. ${ }^{12}$ Since the principal offense is described according to different sections of

\footnotetext{
${ }^{6}$ It is a robust finding that the hazard rate for recidivism peaks soon after the previous criminal event. This is followed by a marked decline and, thereafter, a more modest decline toward the end of the tail ([32]; [49]). It is therefore common, in recidivism research, to estimate continuous-time hazard models based on an assumption that duration dependency would be best described by the log-normal distribution (e.g., [19]; [32]). This pattern of recidivism is also confirmed in the descriptive part of this study. All of the models were therefore reestimated using the lognormal model. The results from the lognormal models were substantially the same. Model fit was evaluated using the Bayesian information criterion (BIC) and the Akaike information criterion (AIC). The evaluation supported the Cox model. Results from the lognormal models and the model fit evaluation are available from the author on request.

${ }^{7}$ Homicide, manslaughter, aggravated assault, involuntary manslaughter, causing danger to another, unlawful threat, insulting behavior, rape, child molestation, robbery, aggravated robbery, violence against a public servant, egregious conduct against a public servant, and violent resistance.

${ }^{8}$ Theft, petty theft, unlawful dispossession, theft of a motor vehicle, and aggravated theft.

${ }^{9}$ Narcotics crime, petty narcotics crime, gross narcotics crime, and other narcotic crimes.

${ }^{10}$ Fraud, fraudulent conduct, gross fraud, receiving stolen gods, embezzlement, withholding property, gross embezzlement, unlawful disposal, bookkeeping crime, tax fraud, and gross tax fraud.

${ }^{11}$ Vandalism, aggravated vandalism, petty vandalism, public endangerment.

12 Reckless driving, aggravated reckless driving, drunk driving, and leaving the scene of an accident.
} 
the penal code, the offense categories may overlap. The sanction type is specified in accordance with a detailed sanctions list. On the basis of this information, the following three dummy variables were coded: prison, ${ }^{13}$ probation, and condition$a l .{ }^{14}$ Product terms of gender and conviction order were included to examine the extent to which conviction order modifies the association between gender and recidivism.

As can be seen from Table 1, the males have accumulated more convictions than the females. A higher proportion of the females have only been convicted once, around $72 \%$, as compared to around $48 \%$ among the males. There is an overrepresentation of males who have accumulated two or more convictions in both absolute and relative terms. For example, around $6.4 \%$ of the males have ten or more convictions, as compared to around $2.6 \%$ of the female sample. ${ }^{15}$ Turning to the age-crime distribution, the trends are similar-convictions become less common with increasing age in both the male and the female samples. However, the males have an earlier onset of conviction than the females. Fifty-four percent of the males were convicted for the first time in adolescence, compared to around $38 \%$ of the females. It is also more common for the females to have been convicted for the first time in later age categories. These criminal career patterns correspond well with previous research on gender, crime, and the life course (see [41]).

The offense-type and sanction-type statistics in Table 1 describe the average number of convictions per person that include a given type of offense or sanction. Violent, vandalism, and traffic offenses are, on average, more common in the male sample, and it is also more common for males to be convicted of property offenses, although the difference here is not very large. The gender differences are negligible, however, when it comes to drug and fraud offenses. On average, the males have accumulated more sanctions than the females regardless of the sanction type, and the difference is most marked in relation to prison sentences. There is no significant difference in the mean number of male and female migration events, but the mortality rate over the follow-up period is somewhat higher among the males.

\section{Results}

The first section below examines the hazard functions and cumulative probability functions for recidivism and repeated recidivism among convicted males and females. The subsequent section then fits the event history regression models, which examine the impact of gender and conviction order on recidivism while controlling for age, offense type, and sanction type.

\footnotetext{
${ }^{13}$ Prison and life imprisonment

${ }^{14}$ Conditional sentence, waiver of prosecution, summary sanction order, and fine.

${ }^{15}$ I want to stress that the conviction order percentages in Table 1 relate to the within-gender distribution of offenders across different conviction orders and not to the risk of recidivism which the following analyses are based on. In other words, the denominators in Table 1 are the total offending populations among males and females, respectively, while the denominator in the measure of recidivism is essentially based on the previous conviction order.
} 
Table 1 Descriptive statistics on offenses and sentencing, by gender

\begin{tabular}{|c|c|c|c|c|c|}
\hline \multirow[b]{2}{*}{ Conviction order } & \multicolumn{2}{|c|}{ Males $(N=27,071)$} & \multicolumn{2}{|c|}{ Females $(N=7531)$} & \multirow[b]{2}{*}{ Chi-square } \\
\hline & Percent & $N$ & Percent & $N$ & \\
\hline $1 \mathrm{st}$ & 48.39 & 13,099 & 71.46 & 5382 & $1261.00^{* * *}$ \\
\hline 2nd & 19.60 & 5305 & 14.30 & 1077 & $109.85^{* * *}$ \\
\hline 3 rd -4 th & 15.47 & 4187 & 7.60 & 572 & $307.76^{* * *}$ \\
\hline 5 th-9th & 10.16 & 2750 & 4.08 & 307 & $270.60 * * *$ \\
\hline 10 th + & 6.39 & 1730 & 2.56 & 193 & $164.48 * * *$ \\
\hline \multicolumn{6}{|l|}{ Age at conviction } \\
\hline $15-19$ & 54.00 & 14,619 & 37.88 & 2853 & $612.40 * * *$ \\
\hline $20-24$ & 42.35 & 11,464 & 30.77 & 2317 & $329.78 * * *$ \\
\hline $25-29$ & 27.38 & 7412 & 20.79 & 1566 & $133.00 * * *$ \\
\hline $30-34$ & 21.57 & 5839 & 16.09 & 1212 & $108.88^{* * *} *$ \\
\hline $35-39$ & 15.91 & 4308 & 12.00 & 904 & $70.41 * * *$ \\
\hline $40+$ & 19.85 & 5373 & 18.18 & 1369 & $10.47 * *$ \\
\hline \multicolumn{6}{|c|}{ Age at first conviction } \\
\hline $15-19$ & 54.00 & 14,619 & 37.88 & 2853 & $612.40 * * *$ \\
\hline $20-24$ & 21.58 & 5843 & 24.39 & 1837 & $26.91 * * *$ \\
\hline $25-29$ & 9.18 & 2486 & 13.40 & 1009 & $115.26^{* * *}$ \\
\hline $30-34$ & 6.49 & 1758 & 9.00 & 678 & $56.66 * * *$ \\
\hline $35-39$ & 3.88 & 1050 & 5.86 & 441 & $55.86 * * *$ \\
\hline $40+$ & 4.86 & 1315 & 9.47 & 713 & $226.94 * * *$ \\
\hline Offense type & Mean & $\mathrm{SD}$ & Mean & $\mathrm{SD}$ & $T$ test \\
\hline Violence & 0.39 & 1.04 & 0.14 & 0.51 & $20.05 * * *$ \\
\hline Property & 0.79 & 2.47 & 0.69 & 1.78 & $3.22 * *$ \\
\hline Drug & 0.17 & 0.94 & 0.15 & 0.78 & 1.64 \\
\hline Fraud & 0.25 & 0.75 & 0.27 & 0.72 & -2.21 \\
\hline Vandalism & 0.14 & 0.44 & 0.04 & 0.24 & $18.79 * * *$ \\
\hline Traffic & 0.97 & 2.19 & 0.44 & 1.25 & $19.93 * * *$ \\
\hline \multicolumn{6}{|l|}{ Sanction type } \\
\hline Prison & 0.46 & 1.94 & 0.12 & 0.82 & $14.55 * * *$ \\
\hline Probation & 0.21 & 0.79 & 0.16 & 0.70 & $4.19 * * *$ \\
\hline Conditional & 2.71 & 4.09 & 1.73 & 2.54 & $19.68 * * *$ \\
\hline \multirow[t]{2}{*}{ Migration events } & 1.79 & 1.29 & 1.80 & 1.33 & -0.18 \\
\hline & Percent & $N$ & Percent & $N$ & Chi-square \\
\hline Deceased & 3.60 & 974 & 2.75 & 207 & $12.89 * * *$ \\
\hline
\end{tabular}

Convicted males and females born in 1965. Two-tailed $t$ test ${ }^{*} p<0.05 ; * * p<0.01 ; * * * p<0.001$

\section{Long-Term Recidivism Patterns among Convicted Males and Females}

Table 2 presents the descriptive statistics for the number of observations, events, and median survival times (i.e., the point at which half of the sample has been reconvicted 


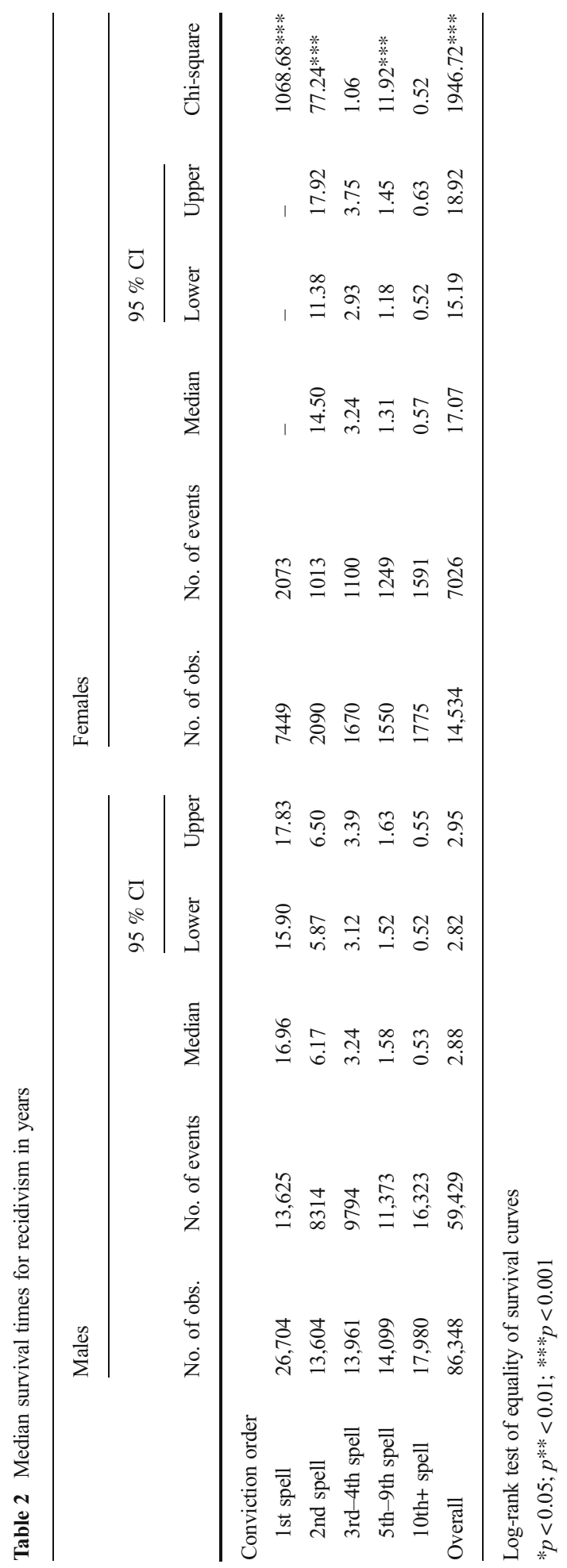


following the previous conviction) by conviction order in convicted males and females, respectively. Table 2 also includes the test statistics. ${ }^{16}$ Viewed over the whole 30 -year observation window, a total of 86,348 periods were observed among the males, of which 59,429 resulted in a reconviction. Among the females, a total of 14,534 periods were observed, of which 7026 resulted in a reconviction. ${ }^{17}$ When convicted males and females are compared with regard to average recidivism tendencies, in terms of median survival times, it becomes clear that a male conviction results in a reconviction substantially more quickly than a female conviction. It took 2.9 years for half of the total number of male convictions to result in a reconviction, compared to over 17 years for the female convictions.

A more nuanced picture is obtained when the male and female median survival times are compared, by conviction order. Initially, it can be noted that there is a consistent decrease in the median survival time to recidivism with subsequent convictions among both males and females. This development reflects the growth in reconviction probabilities in a cohort of offenders (e.g., [52]). Table 2 shows that gender has some predictive value in relation to lower-order recidivism tendencies, particularly when males and females are compared following their first conviction. It took almost 17 years for half of the males to be reconvicted following their first conviction, whereas only $33 \%$ of the females were reconvicted following their first conviction throughout the entire observation period. Following a second conviction, it took around 6.2 years for half of the male sample to be reconvicted, whereas the corresponding number of years for the females, following a second conviction, was 14.5. When the focus is shifted to the higher-order spells, however, there are no significant differences between males and females who have been convicted three or four times, and the same is true for males and females who have experienced their tenth or subsequent conviction. Females who have experienced their fifth to ninth convictions are, on average, reconvicted even more quickly than their male counterparts.

Figure 1 illustrates the first- and second-order processes of recidivism spanning a 30year period among the males and females. As can be seen in the upper left-hand graph in Fig. 1, the hazard curves following a first conviction first increase to a peak, from where they then follow a declining tendency throughout the rest of the follow-up period. The patterns are similar across males and females with a peak in the hazard curves around 2 years after the first conviction. ${ }^{18}$ The males are reconvicted at a higher rate than the females throughout almost the entire follow-up period. This difference is

\footnotetext{
${ }^{16}$ In addition to the presented log-rank test statistics, I also calculated Wilcoxon test statistics. The log-rank test stresses differences at the end of the process time, while the Wilcoxon test stresses differences at the beginning of the process time, and in that sense, they complement each other ([11], p. 81). These test statistics provided the same substantial conclusions of whether to reject the null hypothesis, which add to the confidence of the results.

${ }^{17}$ It must be emphasized that the following analyses are based on events and not individuals. The population in Table 2 thus refers to the number of male and female convictions and not the number of convicted males and females. For example, an individual may contribute to several events when conviction order is collapsed into broader categories (for a distinction between offender- and event-based populations, see Rhodes et al. [54]).

${ }^{18}$ It can be noted that in comparison with recidivism studies using prison populations (e.g., [19]), the peak hazard is, in this study, somewhat postponed. This is not so strange given that this particular study considers a sample of individuals from their first conviction regardless of sanction type. In other words, one might expect the peak to occur earlier in samples characterized by a higher risk.
} 


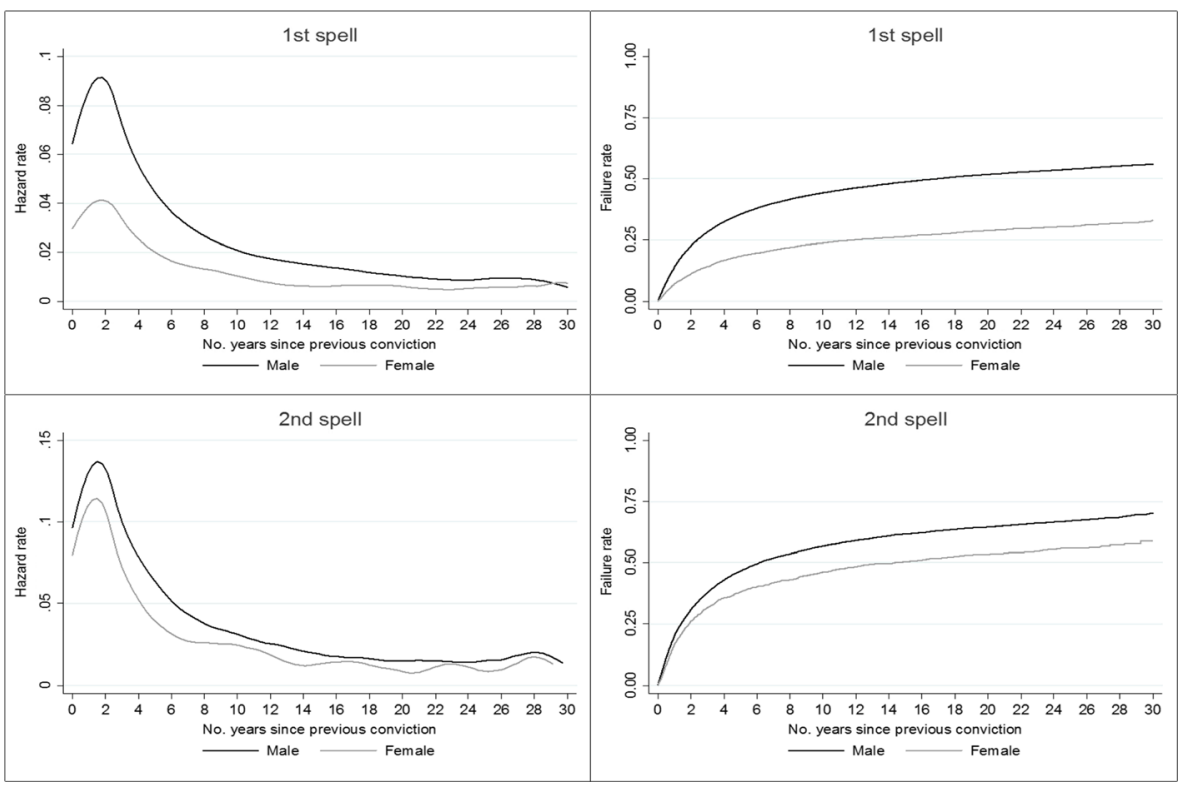

Fig. 1 Lower-order recidivism tendencies among convicted males and females. Smoothed hazard functions (left) and cumulative probability functions (right)

greatest close to the onset conviction, and there is then a tendency toward convergence as time passes. It takes a long time, however, for the recidivism risks of males and females to converge completely following a first conviction. The hazard curves do not converge until 29 years after the onset conviction. As is demonstrated by the upper right-hand graph in Fig. 1, the overall higher rate of recidivism among males following a first conviction leads to them both being reconvicted more quickly and having a higher long-term probability of reconviction than females following a first conviction. Around one quarter of the males are reconvicted within 2.5 years, while it takes almost 12 years for the same proportion of females to be reconvicted. Around $56 \%$ of the males are eventually reconvicted, compared to around $33 \%$ of the females.

Shifting the focus to the situation among males and females following a second conviction, as illustrated by the graphs in the bottom sections of Fig. 1; it can first be noted that the same characteristic recidivism pattern is replicated - the hazard curves following a second conviction first increase to a peak, from where they then follow a declining tendency throughout the rest of the follow-up period. The peak in the hazards has now increased for both males and females (note that the $y$-axes for hazards following a first and second conviction are displayed on different scales), but the difference between the hazard curves for males and females following a second conviction is considerably less pronounced than that found following the first conviction. Nonetheless, males still experience an overall higher, and statistically significant, hazard for recidivism than females following a second conviction, which results in a larger proportion of males being reconvicted following a second conviction. Around $70 \%$ of males with a second conviction are reconvicted again within 30 years, as compared to around $59 \%$ of females with a second conviction. 
Figure 2 illustrates higher-order processes of recidivism spanning a 30-year period among convicted males and females. As can be seen, the characteristic recidivism pattern, as illustrated in Fig. 1, is replicated regardless of the order of the conviction. The hazard curves become even more distinct, with a higher, and somewhat quicker, peak, followed by a steeper decline as the number of convictions increases (again, note the different scales on the $y$-axes of the hazard graphs). As is also shown in Table 2, the magnitude differences that were noted in male and female lower-order recidivism tendencies have now disappeared. Not only are male and female higher-order recidivism patterns parallel, but the rates are now also at similar levels. ${ }^{19}$ When the focus is directed at the relatively small and highly selected groups of males and females with ten or more prior convictions, more than $80 \%$ of these convictions result in a further reconviction within 2 years and more than $95 \%$ eventually result in a reconviction over the full observation window. It can be noted that when it comes to those convicted ten or more times, the observation period ends at around 23 years for the males and at 12 years for the females.

\section{Event History Models of Repeated Recidivism}

Table 3 presents three Cox regression models in which the outcome is defined as the hazard rate to recidivism. The beta coefficients were exponentiated, and the estimates can therefore be interpreted as hazard ratios. The size of the estimate can be interpreted as the factor by which the hazard rate increases/decreases with a one-step increase in the independent variable. In model 1, only the main effect variables of gender and conviction order are included. In model 2 , the product terms of gender and conviction order are added, and model 3 presents the full model, which also includes additional control variables that may confound the associations between gender, conviction order, and recidivism.

As can first be seen from model 1 in Table 3, the hazard rate of recidivism is, on average, $25 \%$ lower among the females than among the males. The conviction order dummies show that the hazard increases with an increasing number of accumulated convictions. For example, the hazard increases by around $54 \%$ for the second conviction relative to the first, and from the tenth conviction and onward, the hazard is close to seven times larger relative to the first. It should also be noted that all of the conviction order estimates are significantly different from each other, as can be seen from the confidence intervals.

Model 2 reveals a dynamic in gender and recidivism that was missed in model 1 . The covariate for gender shows that the hazard among the females is half to that of the males during the first reconviction process (around $53 \%$ lower), and the conviction order dummies show the increase in the hazard among the males that comes from an increasing number of accumulated convictions. The product terms show how this estimate changes as convictions accumulate. The first product term estimate (female

\footnotetext{
${ }^{19}$ It should be noted that the offending populations become smaller for every accumulated conviction and that the number of individuals at risk decreases as time passes because the event (reconviction) occurs or because of censoring. As can be seen, this results in that the hazard functions become somewhat unstable for female higher-order convictions. This is especially apparent in the fifth to ninth spell in the spike of the hazard that occurs after around 25 years. I therefore want to emphasize that it is the overall trends that are of substantial interest and that one should not put much effort in trying to interpret the year-to-year variations in hazards.
} 


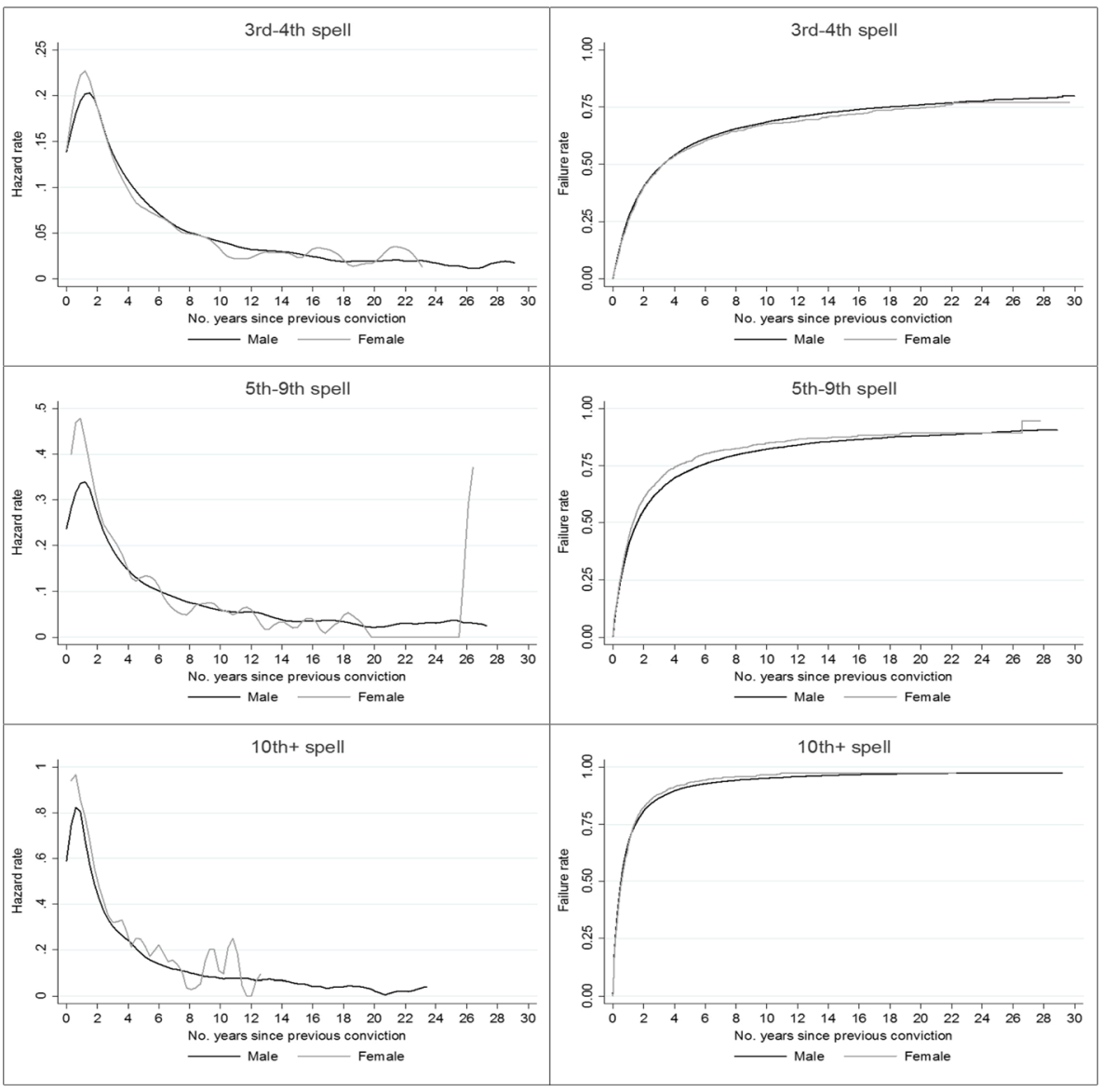

Fig. 2 Higher-order recidivism tendencies among convicted males and females. Smoothed hazard functions (left) and cumulative probability functions (right)

$\times$ second spell) shows that the hazard estimate of being female in the first conviction increases by around 1.6 times when turning to the second conviction. This means that the hazard rate of recidivism among the females is around $25 \%$ lower than that of the males during the second conviction $(0.473 * 1.582)$. Turning to the third to the fourth conviction order, the difference in the hazard rate of recidivism is only around $3 \%$ lower among the females $(0.473 * 2.042)$. In higher-order convictions, there is even a slight over risk of being female. This is most evident when turning to the fifth to the ninth conviction where the hazard rate among the females is around $11 \%$ larger than among the males $(0.473 * 2.343) .^{20}$

\footnotetext{
$\overline{{ }^{20}}$ These interactions may also be expressed by comparing the male and female increase in the hazard rate of recidivism that comes from a certain conviction order relative to a male experiencing his first conviction. For example, as can be seen in model 2 in Table 3, for a male experiencing his fifth to ninth conviction, the hazard of recidivism is almost three times higher (2.982) than a male experiencing a first conviction. For a female experiencing her fifth to ninth conviction, the hazard of recidivism is around 3.3 times higher than a male experiencing a first conviction $(0.473 * 2.982 * 2.343)$.
} 
Table 3 Event history models predicting the survival time to recidivism

\begin{tabular}{|c|c|c|c|c|c|c|c|c|c|}
\hline \multirow[b]{3}{*}{ Covariate } & \multicolumn{3}{|l|}{ Model 1} & \multicolumn{3}{|l|}{ Model 2} & \multicolumn{3}{|l|}{ Model 3} \\
\hline & \multirow[b]{2}{*}{ HR } & \multicolumn{2}{|c|}{$95 \% \mathrm{CI}$} & \multirow[b]{2}{*}{ HR } & \multicolumn{2}{|c|}{$95 \% \mathrm{CI}$} & \multirow[b]{2}{*}{ HR } & \multicolumn{2}{|l|}{$95 \%$ CI } \\
\hline & & Lower & Upper & & Lower & Upper & & Lower & Upper \\
\hline \multicolumn{10}{|l|}{ Gender } \\
\hline Male & 1 & & & 1 & & & 1 & & \\
\hline Female & $0.754 * * *$ & 0.720 & 0.790 & $0.473 * * *$ & 0.452 & 0.496 & $0.498 * * *$ & 0.475 & 0.522 \\
\hline \multicolumn{10}{|l|}{ Conviction order } \\
\hline 1st spell & 1 & & & 1 & & & 1 & & \\
\hline 2nd spell & $1.539 * * *$ & 1.501 & 1.578 & $1.429 * * *$ & 1.392 & 1.466 & $1.762 * * *$ & 1.712 & 1.813 \\
\hline 3 rd -4 th spell & $2.153 * * *$ & 2.100 & 2.208 & $1.954 * * *$ & 1.905 & 2.006 & $2.765 * * *$ & 2.678 & 2.855 \\
\hline 5th-9th spell & $3.315 * * *$ & 3.227 & 3.405 & $2.982 * * *$ & 2.902 & 3.064 & $4.841 * * *$ & 4.667 & 5.021 \\
\hline 10th+ spell & $6.783 * * *$ & 6.530 & 7.046 & $6.155^{* * *}$ & 5.913 & 6.406 & $11.933 * * *$ & 11.380 & 12.512 \\
\hline \multicolumn{10}{|l|}{ Age } \\
\hline \multicolumn{4}{|c|}{ Age at conviction } & & & & $0.793 * * *$ & 0.785 & 0.801 \\
\hline \multicolumn{4}{|c|}{ Age at conviction squared } & & & & $1.003 * * *$ & 1.003 & 1.003 \\
\hline \multicolumn{4}{|c|}{ Age at first conviction } & & & & $1.013 * * *$ & 1.009 & 1.016 \\
\hline \multicolumn{10}{|c|}{ Offense type } \\
\hline \multicolumn{4}{|l|}{ Property } & & & & 1 & & \\
\hline \multicolumn{4}{|l|}{ Violence } & & & & $0.786 * * *$ & 0.763 & 0.810 \\
\hline \multicolumn{4}{|l|}{ Drug } & & & & $1.055 * *$ & 1.014 & 1.097 \\
\hline \multicolumn{4}{|l|}{ Fraud } & & & & $0.906 * * *$ & 0.877 & 0.937 \\
\hline \multicolumn{4}{|l|}{ Vandalism } & & & & $0.833 * * *$ & 0.799 & 0.869 \\
\hline \multicolumn{4}{|l|}{ Traffic } & & & & $0.831 * * *$ & 0.809 & 0.853 \\
\hline \multicolumn{10}{|l|}{ Sanction type } \\
\hline \multicolumn{4}{|l|}{ Probation } & & & & 1 & & \\
\hline \multicolumn{4}{|l|}{ Prison } & & & & $1.144 * * *$ & 1.100 & 1.190 \\
\hline \multicolumn{4}{|l|}{ Conditional } & & & & $0.916 * * *$ & 0.885 & 0.948 \\
\hline Product terms & & & & IE & $95 \% \mathrm{Cl}$ & & IE & $95 \% \mathrm{CI}$ & \\
\hline & & & & & Lower & Upper & & Lower & Upper \\
\hline Female $\times 2$ nd & spell & & & $1.582 * * *$ & 1.461 & 1.712 & $1.603 * * *$ & 1.476 & 1.742 \\
\hline Female $\times 3$ rd - & 4 th spell & & & $2.042 * * *$ & 1.885 & 2.213 & $2.002 * * *$ & 1.838 & 2.181 \\
\hline Female $\times 5$ th - & 9th spell & & & $2.343 * * *$ & 2.152 & 2.551 & $2.338 * * *$ & 2.145 & 2.549 \\
\hline Female $\times 10^{\text {th }}$ & + spell & & & $2.183 * * *$ & 1.940 & 2.457 & $2.148 * * *$ & 1.904 & 2.424 \\
\hline Log likelihood & $-714,811.09$ & & & $-714,422$ & & & $-709,040.38$ & & \\
\hline
\end{tabular}

Significance based on the clustered sandwich estimator

$C I$ confidence interval, $H R$ hazard ratio, $I E$ interaction effect

$* p<0.05 ; * * p<0.01 ; * * * p<0.001$

As can be seen in model 3, the product terms of gender and conviction order remain more or less the same when controlling for criminal career features that may confound the association between gender and recidivism, that is, age, offense type, and sanction variables. In fact, the over risk of being female in higher-order convictions increases 
somewhat - females experiencing their fifth to ninth conviction now have a $16 \%$ higher hazard of recidivism compared to their male counterparts $(0.498 * 2.338)$. The age at conviction covariate shows that the hazard rate of recidivism decreases with age and, taken together with the squared age term, indicates that this association is not linear but increases somewhat in size with increasing age. These age variables thus reflect the previously well-established age-crime curve found in cohorts of offenders [21]. The estimate for age at first conviction shows that the hazard rate is, on average, somewhat increased for offenders who have a later conviction onset relative to offenders who have an earlier conviction onset (the hazard increases by $1.3 \%$ for every year that the conviction onset is postponed). The offense -type dummies all involve comparisons with being convicted of a property offense and indicate that only drug offenses are associated with an increased hazard rate of recidivism $(5.5 \%$ higher hazard rate), while especially a violent offense is associated with a decrease in the hazard rate (around $21 \%$ lower). The sanction dummies show that a prison sanction increases the hazard rate of recidivism by around $14 \%$, by comparison with a probationary sanction.

Finally, the full model was analyzed for males and females separately (Table 4) in order to examine gender similarities and differences in the predictive values of the other criminal career measures. As can be seen in Table 4, all of the estimates go in the same direction. This is in line with previous research showing that gender neutrality in formative experiences conducive to crime is the rule [31]. There are, however, three results that are particularly interesting here. First, the effect sizes of the conviction order dummies are substantially larger among the females. This indicates that the selection into persistence is stronger within the female offending population than within the male offending population. Second, females who are convicted for a drug offense have a higher risk of recidivism than females who are convicted for a property offense, while, among males, these offense categories have the same predictive value. Third, males who are sentenced to a prison term have a higher risk of recidivism than males who are sentenced to a probation term, while these sentences have the same predictive value among the females. It must be stressed that the estimates in Table 4 relate to withingender associations. Therefore, as a final analysis, the ways in which offense type and sanction type modify the predictive value of gender on recidivism were examined. ${ }^{21}$ This analysis showed that both drug offenses and prison terms are more pronounced predictors of recidivism in females than in males.

\section{Discussion and Conclusions}

There is a consensus that males are overrepresented in offending across the life course. This may easily be translated into a conclusion that being male is one of the demographic risk factors for offending. While this is undisputed at the

\footnotetext{
${ }^{21}$ In accordance with model 3 in Table 3, these models included all of the other covariates but only in terms of main effects and no other product terms. For example, when examining the way in which a drug offense modified the association between gender and recidivism, this constituted the only product term in the model. The results from these models are available from the author on request. It may of course be that other interactions can reveal additional dynamics with regard to gendered aspects of continuity and change. For example, the "snare" of drug offending may be more pronounced in an earlier phase of the criminal career among females relative to males. However, a more in-depth analysis was out of the scope for the present study.
} 
Table 4 Event history models predicting the survival time to recidivism.

\begin{tabular}{|c|c|c|c|c|c|c|}
\hline \multirow[b]{3}{*}{ Covariate } & \multicolumn{3}{|l|}{ Males } & \multicolumn{3}{|l|}{ Females } \\
\hline & \multirow[b]{2}{*}{$\mathrm{HR}$} & \multicolumn{2}{|c|}{$95 \% \mathrm{CI}$} & \multirow[b]{2}{*}{ HR } & \multicolumn{2}{|l|}{$95 \% \mathrm{CI}$} \\
\hline & & Lower & Upper & & Lower & Upper \\
\hline \multicolumn{7}{|l|}{ Conviction order } \\
\hline 1st spell & 1 & & & 1 & & \\
\hline 2nd spell & $1.758 * * *$ & 1.707 & 1.810 & $2.606 * * *$ & 2.398 & 2.831 \\
\hline 3 rd-4th spell & $2.760 * * *$ & 2.670 & 2.852 & $4.839 * * *$ & 4.390 & 5.335 \\
\hline 5th-9th spell & $4.840 * * *$ & 4.660 & 5.027 & $9.251 * * *$ & 8.232 & 10.397 \\
\hline 10th+ spell & $11.931 * * *$ & 11.367 & 12.523 & $20.787 * * *$ & 17.697 & 24.417 \\
\hline \multicolumn{7}{|l|}{ Age } \\
\hline Age at conviction & $0.786^{* * * *}$ & 0.777 & 0.795 & $0.890 * * *$ & 0.865 & 0.916 \\
\hline Age at conviction squared & $1.003 * * *$ & 1.003 & 1.004 & $1.001 * * *$ & 1.001 & 1.002 \\
\hline Age at first conviction & $1.007 * *$ & 1.003 & 1.011 & $1.026 * * *$ & 1.018 & 1.035 \\
\hline \multicolumn{7}{|l|}{ Offense type } \\
\hline Property & 1 & & & 1 & & \\
\hline Violence & $0.781 * * *$ & 0.757 & 0.805 & $0.870 * *$ & 0.793 & 0.955 \\
\hline Drug & 1.033 & 0.989 & 1.079 & $1.153 * *$ & 1.058 & 1.256 \\
\hline Fraud & $0.891 * * *$ & 0.859 & 0.925 & 0.957 & 0.886 & 1.034 \\
\hline Vandalism & $0.823 * * *$ & 0.788 & 0.859 & 0.931 & 0.790 & 1.098 \\
\hline Traffic & $0.826^{* * * *}$ & 0.803 & 0.849 & $0.794 * * *$ & 0.725 & 0.869 \\
\hline \multicolumn{7}{|l|}{ Sanction type } \\
\hline Probation & 1 & & & 1 & & \\
\hline Prison & $1.172 * * *$ & 1.124 & 1.223 & 1.052 & 0.937 & 1.181 \\
\hline Conditional & $0.942 * *$ & 0.907 & 0.978 & $0.778 * * *$ & 0.713 & 0.849 \\
\hline Log likelihood & $-625,085.28$ & & & $-61,390.75$ & & \\
\hline
\end{tabular}

The full model separated by gender. Significance based on the clustered sandwich estimator $C I$ confidence interval, $H R$ hazard ratio

$* p<0.05 ; * * p<0.01 ; * * * p<0.001$

population level, however, previous life course and recidivism research has shown that gender is not that important for predicting levels of offending within the offender population, particularly among those who persist in offending. At the same time, no previous research has systematically examined the manner in which the criminal history modifies the predictive value of gender in relation to recidivism over the long run, and longitudinal datasets that follow a substantial number of female offenders from adolescence into adulthood remain rare. This study has utilized population-based register data for an entire Swedish birth cohort followed from age 15 to 47 and in doing so has been able to describe long-term recidivism patterns in a nationally representative sample of convicted males and females. The overarching aim has been to examine how the predictive value of gender varies with criminal history. In 
addition, the descriptive part of the analysis has focused on illustrating recidivism processes in males and females using hazard curves and cumulative probability curves.

Considering the relative rarity of females who enter the criminal justice system, one might think that the female offender population, as early as the first conviction, is composed of a more highly selected and marginalized group than the male offender population. While this may be true with regard to other life course outcomes (see [34]), this study has shown that it is not true with regard to recidivism. Following a first conviction, males recidivate at a higher rate than females, and as is shown by the hazard functions, it takes a considerable amount of time before the respective hazards of males and females even begin to converge. While gender has some predictive validity in relation to reoffending following a first conviction, however, and, to some extent, also following a second conviction, the study's central finding is that those males and females who persist into higher-order convictions are similar in their recidivism risk. When comparing males and females who have a prior record of five to nine convictions, there is even a slight over risk for reoffending among females. These patterns remained when controlling for criminal career parameters that previous research has shown to differ between male and female offenders, that is, age at conviction, conviction onset, offense type, and sanction type. Thus, relatively speaking, the selection into persistent offending seems to be stronger among females than among males.

Previous research has shown that there is a robust pattern of recidivism in males. The risk for recidivism is greatest close to the previous criminal event, after which there is a steep decline, and then a gradual leveling off as time passes (e.g., [49]). As Alfred Blumstein and others have argued, this pattern has strong policy implications because it suggests that the predictive value of a criminal record is highly dependent on the time that has passed since a given conviction, and considering the potential damage that a criminal record may produce in relation to future life chances, this time to redemption should be considered in the handling of criminal records. One important finding in this study is that males and females with an extensive criminal record are not only similar in overall recidivism risk, but also strikingly similar in how their respective recidivism patterns vary over time. Thus, while this study has not examined the exact time to redemption, a research question that would require a comparison group of nonoffenders, it nevertheless shows that a prior criminal record becomes less predictive of a future offense as time passes among males as well as females.

Perhaps the most interesting theoretical questions surrounding the increase in reconviction probabilities are why some persist into higher-order convictions, and correspondingly, why some desist after only one or a few convictions. These questions are linked to a theoretical controversy regarding the relative importance of persistent between-individual differences (i.e., population heterogeneity) versus external events (i.e., state dependency) in explaining the association between past and future offending [46]. State dependency theories posit that there is a causal effect of prior involvement in crime on further participation in crime, while population heterogeneity theories instead attribute continuity in offending to persistent individual traits established early in life. As Laub and Sampson [36] note, state dependence versus population heterogeneity may as well be termed "the kinds of context argument" versus "the kinds of people argument" (p. 24). As such, they are ideal-typical and should not be interpreted as mutually exclusive. Instead, life course theories rather assume that both of these 
processes are in play at the same time. Nevertheless, this dichotomy is useful because it highlights how different theories emphasize different processes in explaining the association between past and future offending and because one cannot assess the relative importance of either one of these processes without taking into account the other [46].

Piquero et al. [51] replicated an earlier study conducted exclusively among males in the Cambridge Study, in order to examine whether the link between past and future criminal convictions could be explained by a similar set of processes among males and females in the Dunedin study. To the author's knowledge, this is the only causal study that has explicitly contrasted population heterogeneity and state dependency processes in relation to offending among females. The researchers used a form of latent class analysis, in which the population heterogeneity hypothesis was that males and females would stay in the same latent rank order of low, medium, or high offending in the transition from adolescence (ages 13 to 17) to adulthood (ages 18 to 26), whereas the state dependence hypothesis was that the rankings of males and females would change. Piquero et al. [51] found that the population heterogeneity model provided a good fit to the data and therefore concluded that "substantial individual differences in the tendency to persist in criminal activity are formed by the end of adolescence." They argued further that the results indicate that the ways in which crime suppresses (or triggers) life transitions are themselves contingent on the situation in adolescence (p. 238).

Moffitt et al. [45] argue, in line with a gender-neutral approach to continuity in offending, that the origins of life course persistent antisocial behavior are to be found early in life for both males and females and stem from much the same childhood risk factors of poor discipline, family adversity, cognitive deficits, an under-controlled temperament, hyperactivity, and rejection by peers (p. 226). The magnitude difference between male and female offending over the life course is, according to Moffitt et al. [45], due to males being more exposed to those childhood risk factors presumed to be most important. The paradox here is that although females are generally at lower risk of developing a persistent criminal career, it seems that those who do so are likely to be even more deviant and marginalized than their male counterparts. For example, Lanctôt et al. [34] studied male and female samples of institutionalized youths and found that the females faced the most adverse conditions in the transition to young adulthood with regard to multiple life domains. Similarly, the Swedish IDA study, in which a normative sample of males and females was followed from age 10 into their mid-40s (see [8]), found that drug, alcohol, and mental health problems were a more pronounced feature in the group of persistent female offenders than among persistent male offenders (see also [25]). According to Steffensmeier and Allan [56], this may be due to the gap between femininity and crime being wider than that between masculinity and crime: "Crime is almost always stigmatizing for females, and its potential cost to life chances is much greater than for males" (p. 476). Therefore, to the extent that stigmatization and social exclusion are associated with recidivism, the growth in reconviction probabilities may also be related to processes of state dependency and perhaps more so in females than in males.

One of the hypothesized "snares" underlying the state dependency argument is drug addiction [34, 44, 48]. Given that the present study employed conviction data, a drug offense in the current context is likely to indicate serious drug use rather than minor substance and alcohol use (see [25]). As this study shows, drug offenses, together with 
property offenses, constitutes one of the offense types that most typically results in a reconviction among both males and females, but particularly among females (see also $[5,57])$. However, more research is needed to assess whether drug abuse is a snare in the causal meaning of the term and also whether it is a more important explanatory factor among females than among males. In particular, future research focused on evaluating processes of state dependency in males and females should employ fixedeffects methods on repeated events, thereby using every individual as his or her own control (see [1]).

Recidivism has, in the current study, been defined as having been reconvicted. A reconviction may be characterized as a "back-end" measure of recidivism in comparison with a rearrest [49], thereby excluding less serious offenders and also providing for less official bias resulting from police behavior. Still, a reconviction may be considered a rather broad definition of recidivism, and there may be systematic gender differences in this regard. In order to dig deeper into the interaction between gender and criminal history on recidivism patterns, future studies should employ competing risk analysis where the outcome is nuanced into different measures of recidivism, for example, based on the offense type and/or type of sanction. The current study has also been limited to focusing on typical criminal career parameters and their associations with recidivism. In order to further understand and explain gender similarities and differences in recidivism patterns, future research should include other domains of the life course into the analysis. In addition, it is important to note that formative experiences conducive to crime may be relatively gender-neutral, but that "the emotional mediators of these experiences and the opportunities for offending may not be" ([31], p. 296). More indepth analyses contrasting males and females are therefore needed to further reveal the role of state dependency mechanisms in continuity and change in crime.

In line with a recent trend in long-term recidivism research (e.g., [32]), the argument in this study has been that event history methods are useful in studying continuity and change in criminal offending because these methods utilize the timing aspect of recidivism. As Hagan and Palloni [29] argued a long time ago, the employment of these methods is a way of acknowledging crimes as social events in the life course and thereby of connecting with the larger life course literature. Every criminal event over the study period may, in this methodological framework, be recognized, not only as an outcome of some distant past, but also as a possible cause in relation to future criminal events. In this regard, it should be noted that the impact of being convicted on recidivism (and other life course outcomes) might depend on the developmental stage of the criminal career. In light of the increase in reconviction probabilities, MacLeod et al. [40] have argued that recidivism risk may increase as a consequence of offenders becoming entrenched in the criminal lifestyle and finding it progressively more difficult to rejoin mainstream society, but that this is a plausible explanation only for the first six convictions and not for continued offending after this point (p. 200). In a similar manner, there are studies assessing the impact of incarceration on recidivism risk that focus particularly on persons imprisoned for the first time on the basis of the argument that this population may be particularly vulnerable to the hypothesized criminogenic effects of imprisonment (e.g., [55]). In general, future research in developmental and life course criminology should dig deeper into the dynamics of recidivism and, among other things, acknowledge that the impact on recidivism of being convicted may be dependent on the phase in the criminal career. 
This study has shown that the female offending population becomes increasingly similar to the male offending population in terms of recidivism risk as convictions accumulate. The two groups are hardly separable from as early as the transition from the third to the fourth conviction. Not only are males and females similar in their respective reconviction rates from this point on in the criminal career, they are also similar in the manner in which their risk of relapse varies over time. The risk of recidivism is highest close to the previous criminal event, after which there is a steep decline, and then a gradual leveling off as time passes. In other words, those who relapse into a new conviction tend to do so quite soon after the previous conviction, and this pattern is particularly pronounced among those offenders who accumulate an extensive criminal record. On the one hand, this is a sad story for a relatively small group of repeat offenders, which includes not only males, but also females. On the other hand, the consistency of the declining tendency in recidivism over time provides some hope, in that time may be an essential factor for understanding the mechanisms underlying the return to conventional society.

Acknowledgments I would like to thank Associate Professor Olof Bäckman at the Swedish Institute for Social Research (SOFI), Stockholm University, for his help in providing the data for this study. The study has been conducted within a larger life course project financed by the Swedish Research Council (VR).

\section{References}

1. Allison, P. D. (2009). Fixed effects regression models. Thousand Oaks, CA: SAGE Publications Inc.

2. Allison, P. D. (2014). Event history and survival analysis. Thousand Oaks, CA: SAGE Publications Inc.

3. Andersson, J. (1990). Continuity in crime: sex and age differences. Journal of Quantitative Criminology, $6(1), 85-100$.

4. Andersson, F., Levander, S., Svensson, R., \& Torstensson-Levander, M. (2012). Sex differences in offending trajectories in a Swedish cohort. Criminal Behaviour and Mental Health, 22(2), 108-121.

5. Andrews, D. A., Guzzo, L., Raynor, P., Rowe, R. C., Rettinger, L. J., Brews, A., \& Wormith, J. S. (2012). Are the major risk/need factors predictive of both female and male reoffending? A test with the eight domains of the Level of Service/Case Management Inventory. International Journal of Offender Therapy and Comparative Criminology, 56(1), 113-133.

6. Bäckman, O., Estrada, F., Nilsson, A., \& Shannon, D. (2014). The life course of young male and female offenders: stability or change between different birth cohorts? British Journal of Criminology, 54(3), 393410.

7. Benda, B. B. (2005). Gender differences in life-course theory of recidivism: a survival analysis. International Journal of Offender Therapy and Comparative Criminology, 49(3), 325-342.

8. Bergman, L. R., \& Andershed, A. K. (2009). Predictors and outcomes of persistent or adolescent agelimited registered criminal behavior: a 30-year longitudinal study of a Swedish urban population. Aggressive Behavior, 35(2), 164-178.

9. Bernardi, F. (2001). Is it a timing or a probability effect? Four simulations and an application of transition rate models to the analysis of unemployment exit. Quality and Quantity, 35(3), 231-252.

10. Block, C. R., Blokland, A. J., van der Werff, C., van Os, R., \& Nieuwbeerta, P. (2010). Long-term patterns of offending in women. Feminist Criminology, 5(1), 73-107.

11. Blossfeld, H., Golsch, K., \& Rohwer, G. (2007). Event history analysis with Stata. Mahwah, N.J.: Lawrence Erlbaum Associates.

12. Blumstein, A., Cohen, J., \& Farrington, D. (1988). Criminal career research: its value for criminology. Criminology, 26(1), 1-36.

13. Blumstein, A., \& Nakamura, K. (2009). Redemption in the presence of widespread criminal background checks. Criminology, 47(2), 327-359. 
14. Bushway, S. D., Brame, R., \& Paternoster, R. (2004). Connecting desistance and recidivism: measuring changes in criminality over the lifespan. In S. Maruna \& R. Immarigeon (Eds.), After crime and punishment: pathways to offender reintegration (pp. 85-101). New York: Willan Publishing.

15. Bushway, S. D., Nieuwbeerta, P., \& Blokland, A. (2011). The predictive value of criminal background checks: do age and criminal history affect time to redemption? Criminology, 49(1), 27-60.

16. Bushway, S. D., Thornberry, T. P., \& Krohn, M. D. (2003). Desistance as a developmental process: a comparison of static and dynamic approaches. Journal of Quantitative Criminology, 19(2), 129-153.

17. Cauffman, E., Monahan, K. C., \& Thomas, A. G. (2015). Pathways to persistence: female offending from 14 to 25. Journal of Developmental and Life-Course Criminology, 1(3), 236-268.

18. Curry, T. R. (2014). The benefits and penalties of gender for criminal justice processing outcomes among adults and juveniles. In R. Gartner \& B. McCarthy (Eds.), The Oxford handbook of gender, sex, and crime (pp. 551-571). New York, NY: Oxford University Press.

19. Dejong, C. (1997). Survival analysis and specific deterrence: integrating theoretical and empirical models of recidivism. Criminology, 35(4), 561-576.

20. DeLisi, M. (2002). Not just a boy's club: an empirical assessment of female career criminals. Women \& Criminal Justice, 13(4), 27-45.

21. DeLisi, M., \& Piquero, A. R. (2011). New frontiers in criminal careers research, 2000-2011: a state-ofthe-art review. Journal of Criminal Justice, 39(4), 289-301.

22. D’Unger, A. V., Land, K. C., \& McCall, P. L. (2002). Sex differences in age patterns of delinquent/ criminal careers: results from Poisson latent class analyses of the Philadelphia cohort study. Journal of Quantitative Criminology, 18(4), 349-375.

23. Durose, M. R., Cooper, A. D., \& Snyder, H. N. (2014). Recidivism of prisoners released in 30 states in 2005: patterns from 2005 to 2010. Washington, DC: Bureau of Justice Statistics.

24. Elonheimo, H., Gyllenberg, D., Huttunen, J., Ristkari, T., Sillanmäki, L., \& Sourander, A. (2014). Criminal offending among males and females between ages 15 and 30 in a population-based nationwide 1981 birth cohort: results from the FinnCrime study. Journal of Adolescence, 37(8), 1269-1279.

25. Estrada, F., \& Nilsson, A. (2012). Does it cost more to be a female offender? A life-course study of childhood circumstances, crime, drug abuse, and living conditions. Feminist Criminology, 7(3), 196-219.

26. Ezell, M. E., Land, K. C., \& Cohen, L. E. (2003). Modeling multiple failure time data: a survey of variance-corrected proportional hazards models with empirical applications to arrest data. Sociological Methodology, 22(1), 111-167.

27. Gartner, R. (2011). Sex, gender, and crime. In M. H. Tonry (Ed.), The Oxford handbook of crime and criminal justice (pp. 348-384). New York: Oxford.

28. Giordano, P. C., Cernkovich, S. A., \& Rudolph, J. L. (2002). Gender, crime, and desistance: toward a theory of cognitive transformation1. American Journal of Sociology, 107(4), 990-1064.

29. Hagan, J., \& Palloni, A. (1988). Crimes as social events in the life course: reconceiving a criminological controversy. Criminology, 26(1), 87-100.

30. Hirschi, T., \& Gottfredson, M. (1983). Age and the explanation of crime. American Journal of Sociology, 89(3), 552-584.

31. Kruttschnitt, C. (2013). Gender and crime. Annual Review of Sociology, 39, 291-308.

32. Kurlychek, M. C., Bushway, S. D., \& Brame, R. (2012). Long-term crime desistance and recidivism patterns - evidence from the Essex County convicted felon study. Criminology, 50(1), 71-103.

33. Kyvsgaard, B. (2002). The criminal career: the Danish longitudinal study. Cambridge: Cambridge University Press.

34. Lanctôt, N., Cernkovich, S. A., \& Giordano, P. C. (2007). Delinquent behavior, official delinquency, and gender: consequences for adulthood functioning and well-being*. Criminology, 45(1), 131-157.

35. Lappi-Seppälä, T., \& Tonry, M. (2011). Crime, criminal justice, and criminology in the Nordic countries. Crime and Justice, 40(1), 1-32.

36. Laub, J. H., \& Sampson, R. J. (2003). Shared beginnings, divergent lives: delinquent boys to age 70. Cambridge, MA: Harvard University Press.

37. Leverentz, A. M. (2006). The love of a good man? Romantic relationships as a source of support or hindrance for female ex-offenders. Journal of Research in Crime and Delinquency, 43(4), 459-488.

38. Liu, S. (2015). Is the shape of the age-crime curve invariant by sex? Evidence from a national sample with flexible non-parametric modeling. Journal of Quantitative Criminology, 31(1), 93-123.

39. Lyngstad, T. H., \& Skardhamar, T. (2011). Nordic register data and their untapped potential for criminological knowledge. Crime and Justice, 40(1), 613-645.

40. MacLeod, J. F., Grove, P. G., \& Farrington, D. P. (2012). Explaining criminal careers: implications for justice policy. New York: Oxford University Press. 
41. Macmillan, R., \& McCarthy, B. (2014). Gender and offending in a life course context. In R. Gartner \& B. McCarthy (Eds.), The Oxford handbook of gender, sex, and crime (pp. 343-361). New York, NY: Oxford University Press.

42. Mazerolle, P., Brame, R., Paternoster, R., Piquero, A., \& Dean, C. (2000). Onset age, persistence, and offending versatility: comparisons across gender. Criminology, 38(4), 1143-1172.

43. McGee, T. R., \& Farrington, D. P. (2010). Are there any true adult-onset offenders? British Journal of Criminology, 50(3), 530-549.

44. McGee, T. R., Hayatbakhsh, M. R., Bor, W., Aird, R. L., Dean, A. J., \& Najman, J. M. (2015). The impact of snares on the continuity of adolescent-onset antisocial behaviour: a test of Moffitt's developmental taxonomy. Australian \& New Zealand Journal of Criminology, 48(3), 345-366.

45. Moffitt, T. E., Caspi, A., Rutter, M., \& Silva, P. A. (2001). Sex differences in antisocial behaviour: conduct disorder, delinquency, and violence in the Dunedin longitudinal study. Cambridge, UK: Cambridge University Press.

46. Nagin, D., \& Paternoster, R. (2000). Population heterogeneity and state dependence: state of the evidence and directions for future research. Journal of Quantitative Criminology, 16(2), 117-144.

47. Nilsson, A. (2003). Living conditions, social exclusion and recidivism among prison inmates. Journal of Scandinavian Studies in Criminology and Crime Prevention, 4(1), 57-83.

48. Nilsson, A., Estrada, F., \& Bäckman, O. (2014). Offending, drug abuse and life chances - a longitudinal study of a Stockholm birth cohort. Journal of Scandinavian Studies in Criminology and Crime Prevention, 15(2), 128-142.

49. Nygaard Andersen, S., \& Skardhamar, T. (2014). Pick a number: mapping recidivism measures and their consequences. Discussion papers No. 772, Statistics Norway Research Department.

50. Opsal, T. (2011). Women disrupting a marginalized identity: subverting the parolee identity through narrative. Journal of Contemporary Ethnography, 40(2), 135-167.

51. Piquero, A. R., Brame, R., \& Moffitt, T. E. (2005). Extending the study of continuity and change: gender differences in the linkage between adolescent and adult offending. Journal of Quantitative Criminology, 21(2), 219-243.

52. Piquero, A. R., Farrington, D. P., \& Blumstein, A. (2007). Key issues in criminal career research: new analyses of the Cambridge study in delinquent development. Cambridge: Cambridge University Press.

53. Rhodes, W. (1989). The criminal career: estimates of the duration and frequency of crime commission. Journal of Quantitative Criminology, 5(1), 3-32.

54. Rhodes, W., Gaes, G., Luallen, J., Kling, R., Rich, T., \& Shively, M. (2014). Following incarceration, most released offenders never return to prison. Crime \& Delinquency, 0011128714549655.

55. Sirén, R., \& Savolainen, J. (2013). No evidence of specific deterrence under penal moderation: imprisonment and recidivism in Finland. Journal of Scandinavian Studies in Criminology and Crime Prevention, 14(2), 80-97.

56. Steffensmeier, D., \& Allan, E. (1996). Gender and crime: toward a gendered theory of female offending. Annual Review of Sociology, 22, 459-487.

57. Uggen, C., \& Kruttschnitt, C. (1998). Crime in the breaking: gender differences in desistance. Law and Society Review, 32(2), 339-366.

58. Wikström, P. O. H. (1990). Age and crime in a Stockholm cohort. Journal of Quantitative Criminology, $6(1), 61-84$. 